\title{
Chiral recognition of protected amino acids by means of fluorescent binary complex pyrene/ heptakis-(6-amino)-(6-deoxy)- $\beta$-cyclodextrin
}

\author{
Serena Riela, Francesca D’Anna,* Paolo Lo Meo, Michelangelo Gruttadauria, \\ Rosalia Giacalone and Renato Noto* \\ Dipartimento di Chimica Organica 'E. Paternò', Università degli Studi di Palermo, \\ Viale delle Scienze-Parco d'Orleans II, 90128 Palermo, Italy
}

Received 13 December 2005; revised 10 February 2006; accepted 23 February 2006

\begin{abstract}
The ability of the binary complex pyrene (Py)/heptakis-(6-amino)-(6-deoxy)- $\beta$-cyclodextrin (am- $\beta$-CD) to act as a chiral selector was tested at two $\mathrm{pH}$ values (8.0 and 9.0). Phenylalanine (Phe), methionine (Met) and histidine (His) were used as chiral model molecules. The stability of ternary complexes Py/am- $\beta-C D / a m i n o$ acid was determined by means of spectrofluorimetric measurements. The data collected showed an increase in stability going from the binary to ternary complex and above all the possibility to use the binary complex as a chiral selector. Finally, data collected at two $\mathrm{pH}$ values showed that the binary complex is a better chiral selector when charged rather than in its neutral form.

(C) 2006 Published by Elsevier Ltd.
\end{abstract}

\section{Introduction}

Chiral recognition is one of the most important topics in modern organic chemistry. Probably this is a consequence of the presence of chiral selectors in nature. For example, biological systems only use L-amino acids for protein synthesis. As amino acids and their derivatives are very important in biological systems, the main target of many studies has been the synthesis of macrocyclic receptors able to discriminate between their enantiomers. ${ }^{1}$ On this subject, many different approaches have been tested such as the use of metal complexes, ${ }^{2}$ imprinted polymers ${ }^{3}$ and synthetic macrocycles like calixarenes ${ }^{4}$ and cyclodextrins. ${ }^{5}$ All these systems are generally considered as models of biological systems and could be used to identify the hierarchy of factors governing chiral recognition. Recently, Imai et al. ${ }^{2 b}$ have reported data about the chiral recognition ability of a water soluble zinc porphyrin versus some $\alpha$-amino acids and peptides, which shows enantioselectivity ratios ranging from 1.2 up to 3.3. Likewise Yatsimirsky et al. ${ }^{6}$ have reported data about the chiral recognition ability of $N, N^{\prime}$ dibenzylated $S, S-(+)$ tetrandrine (DBT) versus some $\alpha$-amino acids and corresponding $N$-acetyl derivatives.

\footnotetext{
Keywords: Cyclodextrin; Chiral recognition; Fluorescence.

* Corresponding authors. Tel.: + 39 091596919; fax: + 39091596825

(F.D.); tel.: + 39 091596919; fax: + 39091596825 (R.N.);

e-mail addresses: fdanna@unipa.it; rnoto@unipa.it
}

Differently from other macrocyclic hosts, this latter shows higher affinity and higher enantioselectivity with smaller guests such as $N$-acetylalanine $\left(K_{\mathrm{S}} / K_{\mathrm{R}}\right) \geq 10$.

Among macrocyclic hosts previously considered, cyclodextrins, formed by six $(\alpha-C D)$, seven $(\beta-C D)$ or eight $(\gamma-C D)$ $\alpha$-(D)-glucopyranose units, can act as chiral selectors owing to their intrinsically chiral cavity. Different studies, previously reported, have shown that their chiral discrimination ability with some $\alpha$-amino acids or small peptides could be due to the presence of substituents on the primary or secondary rim. These can change not only the molecular, but also chiral recognition ability of cyclodextrin. ${ }^{7}$ Alternatively, discrimination could be a consequence of the formation of a ternary complex among a functionalised cyclodextrin, a metal ion and a chiral molecule. ${ }^{8}$ Charged cyclodextrins have often been used to study chiral recognition processes. On this subject, Lincoln et al. have studied the chiral recognition of 2-phenylpropanoic acid by mono-(6-amino)-(6-deoxy)- $\beta$-CD. ${ }^{9}$ Likewise the enantiomers of guests having chiral center have been separated by capillary zone electrophoresis using cationic cyclodextrins. ${ }^{10}$ To identify new systems able to act as chiral selectors, a few years ago, we reported data about the stability and the chiral recognition ability of the binary complex formed by pyrene $(\mathbf{P y})$ in the presence of heptakis(6-amino)-(6-deoxy)- $\beta$-cyclodextrin $(\mathrm{am}-\beta-\mathrm{CD})$ and we 
pointed out the good chiral recognition ability of the system versus some $\alpha$-amino acids and their corresponding methyl esters. ${ }^{11}$ In our opinion, this ability was due to the empty volume of the cyclodextrin cavity that, after the inclusion of the Py molecule, can be differently taken up by amino acid enantiomers. Recently, we have reported results about the chiral discrimination ability of the binary complexes formed by $\mathbf{P y}$, xanthone and anthraquinone in the presence of both $\beta$-cyclodextrin and am- $\beta$-CD versus enantiomers of phenylalanine, methionine and histidine. ${ }^{12}$ Collected data have shown that the chiral discrimination ability is influenced by the structure of the fluorescent guest and the binary complex symmetry. In this light, both in the presence of the $\beta-C D$ and am- $\beta-C D$, the binary complex formed by $\mathbf{P y}$ was the best chiral selector. Now, to evaluate how different substitution on the carboxy or amino group of the amino acid can influence both the molecular and chiral discrimination ability of the binary complex Py/am- $\beta-C D$, in this work we report data about the behaviour of some $N$ - and $O$-protected $\alpha$-amino acids; phenylalanine (Phe), methionine (Met) and histidine (His) (Fig. 1).
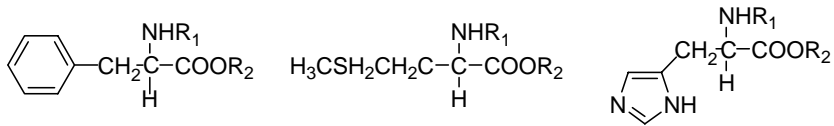

Phe, Met, His

$$
\begin{array}{lc}
\mathrm{R}_{1}=\mathrm{H} & \mathrm{R}_{2}=\mathrm{H} \\
\mathrm{R}_{1}=\mathrm{H} ; & \mathrm{R}_{2}=\mathrm{Me} ; t-\mathrm{Bu} \\
\mathrm{R}_{1}=\mathrm{COCH}_{3} ; \operatorname{COC}\left(\mathrm{CH}_{3}\right)_{3} ; \mathrm{COCH}_{2} \mathrm{Ph} ; & \mathrm{R}_{2}=\mathrm{H}
\end{array}
$$

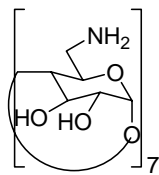

Am- $\beta-C D$

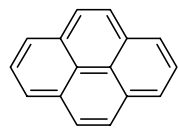

Py
Figure 1. Ternary agents, fluorophore and host structure.

This study was carried out by spectrofluorimetric titration, in borate buffer solution at $\mathrm{pH} 8.0$ and 9.0, to evaluate how the different charge on the host and consequently on the binary complex can influence the interaction with a ternary agent.

\section{Results and discussion}

In Tables 1 and 2 , the stability constant values $\left(\beta_{2}\right)$ for the ternary complexes formed in the presence of amides and esters are reported. In these Tables, the $\beta_{2}$ values of the binary complex Py/am- $\beta-C D$ and its ternary complexes formed in the presence of amino acids are also reported. ${ }^{11}$

As can be seen from the Tables, in all cases, the complexation of fluorophore to am- $\beta-\mathrm{CD}$ can be described by sequential complexation of cyclodextrin molecules
Table 1. Stability constant values $\left(\beta_{2}\right)$ of binary complexes $\mathbf{P y} / \mathbf{a m}-\beta-\mathrm{CD}$ in the presence of amides of amino acids

\begin{tabular}{lcl}
\hline Ternary agent & $\begin{array}{l}\beta_{2}\left(\mathrm{M}^{-2}\right) / 10^{6 \mathrm{a}} \\
\mathrm{pH} 8.0\end{array}$ & $\begin{array}{l}\beta_{2}\left(\mathrm{M}^{-2}\right) / 10^{6 \mathrm{a}} \\
\mathrm{pH} 9.0\end{array}$ \\
\hline None & $1.7^{\mathrm{b}}$ & $4.8^{\mathrm{b}}$ \\
L-Phe & $8.9^{\mathrm{b}}$ & $5.2^{\mathrm{b}}$ \\
D-Phe & $1.2^{\mathrm{b}}$ & $7.6^{\mathrm{b}}$ \\
$N$-Ac-L-Phe & 4.4 & 5.8 \\
$N$-Ac-D-Phe & 24.9 & 2.7 \\
$N$-Boc-L-Phe & 1.4 & 15.2 \\
$N$-Boc-D-Phe & 3.0 & 33.2 \\
$N$-Cbz-L-Phe & 3.6 & n.d. \\
$N$-Cbz-D-Phe & 8.3 & n.d. \\
L-Met & $13.6^{\mathrm{b}}$ & $2.2^{\mathrm{b}}$ \\
D-Met & $2.5^{\mathrm{b}}$ & $5.4^{\mathrm{b}}$ \\
$N$-Ac-L-Met & 5.9 & 10.4 \\
$N$-Ac-D-Met & 12.2 & 8.7 \\
$N$-Boc-L-Met & 5.9 & 15.8 \\
$N$-Boc-D-Met & 3.2 & 32.2 \\
$N$-Cbz-L-Met & 2.6 & 6.2 \\
$N$-Cbz-D-Met & 3.3 & 3.3 \\
L-His & $7.9^{\mathrm{b}}$ & $6.2^{\mathrm{b}}$ \\
D-His & $6.5^{\mathrm{b}}$ & $3.5^{\mathrm{b}}$ \\
$N$-Ac-L-His & 2.2 & 8.0 \\
$N$-Ac-D-His & 3.6 & 6.9 \\
$N$-Boc-L-His & 1.2 & 12.1 \\
$N$-Boc-D-His & 5.6 & 10.7 \\
$N$-Cbz-L-His & 3.7 & 6.8 \\
$N$-Cbz-D-His & 3.0 & 7.0 \\
\hline
\end{tabular}

${ }^{a}$ Stability constant values are reproducible within $10 \%$.

${ }^{\mathrm{b}}$ See Ref. 11.

(Eqs. 1 and 2): ${ }^{13}$

$\mathrm{S}+\mathrm{CD} \stackrel{K_{1}}{\rightleftharpoons} \mathrm{SCD}$

$\mathrm{SCD}+\mathrm{CD} \stackrel{K_{2}}{\rightleftharpoons} \mathrm{S}(\mathrm{CD})_{2}$

\begin{tabular}{|c|c|c|}
\hline Ternary agent & $\begin{array}{l}\beta_{2}\left(\mathrm{M}^{-2}\right) / 10^{6 \mathrm{a}} \\
\mathrm{pH} 8.0\end{array}$ & $\begin{array}{l}\beta_{2}\left(\mathrm{M}^{-2}\right) / 10^{6 \mathrm{a}} \\
\mathrm{pH} 9.0\end{array}$ \\
\hline None & $1.7^{\mathrm{b}}$ & $4.8^{\mathrm{b}}$ \\
\hline L-Phe & $8.9^{\mathrm{b}}$ & $5.2^{\mathrm{b}}$ \\
\hline D-Phe & $1.2^{\mathrm{b}}$ & $7.6^{\mathrm{b}}$ \\
\hline L-PheMe & $2.7^{\mathrm{b}}$ & $3.9^{\mathrm{b}}$ \\
\hline D-PheMe & $19.3^{b}$ & $21.7^{\mathrm{b}}$ \\
\hline L-Phe- $t$-Bu & 7.3 & n.d. \\
\hline $\mathrm{D}-\mathrm{Phe}-t$-Bu & 9.6 & n.d. \\
\hline L-Met & $13.6^{\mathrm{b}}$ & $2.2^{\mathrm{b}}$ \\
\hline D-Met & $2.5^{\mathrm{b}}$ & $5.4^{\mathrm{b}}$ \\
\hline L-MetMe & $2.5^{\mathrm{b}}$ & $1.6^{\mathrm{b}}$ \\
\hline D-MetMe & $29.0^{\mathrm{b}}$ & $5.1^{\mathrm{b}}$ \\
\hline L-Met- $t$-Bu & 3.4 & 5.1 \\
\hline D-Met- $t$-Bu & 4.6 & 3.9 \\
\hline L-His & $7.9^{\mathrm{b}}$ & $6.2^{\mathrm{b}}$ \\
\hline D-His & $6.5^{\mathrm{b}}$ & $3.5^{\mathrm{b}}$ \\
\hline L-HisMe & $1.6^{\mathrm{b}}$ & $3.1^{\mathrm{b}}$ \\
\hline D-HisMe & $3.8^{\mathrm{b}}$ & $2.3^{\mathrm{b}}$ \\
\hline L-His- $t$-Bu & 1.0 & 3.8 \\
\hline $\mathrm{D}-\mathrm{His}-t-\mathrm{Bu}$ & 1.4 & 4.4 \\
\hline
\end{tabular}

In the presence of a ternary agent $K_{1}$ and $K_{2}$ are conditional equilibrium constants since they include a term related to the ternary agent concentration. The overall association

Table 2. Stability constant values $\left(\beta_{2}\right)$ of binary complexes Py/am- $\beta-C D$ in the presence of esters of amino acids

${ }^{\text {a }}$ Stability constant values are reproducible within $10 \%$.

b See Ref. 11. 
constant $\beta_{2}$ will be given by Eq. 3:

$\beta_{2}=K_{1} K_{2}=\left[\mathrm{S}(\mathrm{CD})_{2}\right] /\left([\mathrm{S}][\mathrm{CD}]_{2}\right)$

If $[\mathrm{CD}] \gg[\mathrm{S}]$ the change in the fluorescence intensity as function of $\mathrm{CD}$ concentration will be given by Eq. 4 :

$\Delta I=\left(\Delta \alpha \beta_{2} \mathrm{~S}_{\mathrm{t}}\left[\mathrm{CD}_{0}\right]^{2}\right) /\left(1+\beta_{2}\left[\mathrm{CD}_{0}\right]^{2}\right)$

where $\Delta \alpha$ is the difference of emission quantum yields of free and complexed $\mathbf{P y}$, and $\mathrm{S}_{\mathrm{t}}$ and $\mathrm{CD}_{0}$ are the total concentration of the $\mathbf{P y}$ and am- $\beta-\mathrm{CD}$, respectively. The Eq. 4 is the non-linearised version of Benesi-Hildebrand treatment. ${ }^{14}$ A typical plot of $\Delta I$ as a function of $\left[\mathrm{CD}_{0}\right]^{2}$ is shown in Figure 2.

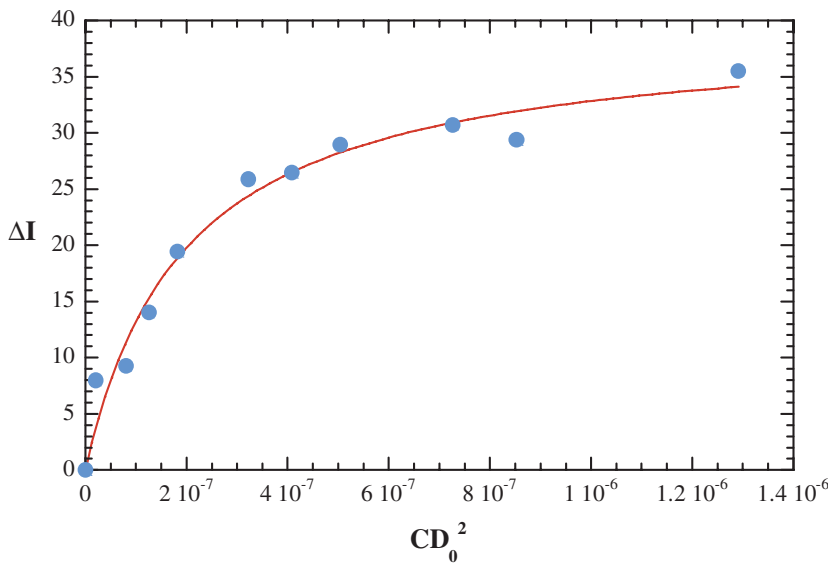

Figure 2. Curve fitting analysis of fluorescence spectral titration of $\mathbf{P y}$ with am- $\beta-C D$ in the presence of $N$-Cbz-L-Phe in borate buffer solution at $\mathrm{pH} 9.0$.

The fluorophore used in this work normally shows a good sensitivity to microenvironmental changes. Indeed, upon its inclusion into the am- $\beta-C D$ cavity, the luminescence is enhanced because the guest molecule is shielded from quenching and non-radiative processes that occur in the bulk solution. $^{15}$ Typical fluorescence spectral changes upon addition of am- $\beta-C D$ to a $\mathbf{P y}$ and ternary agent solution are shown in Figure 3.

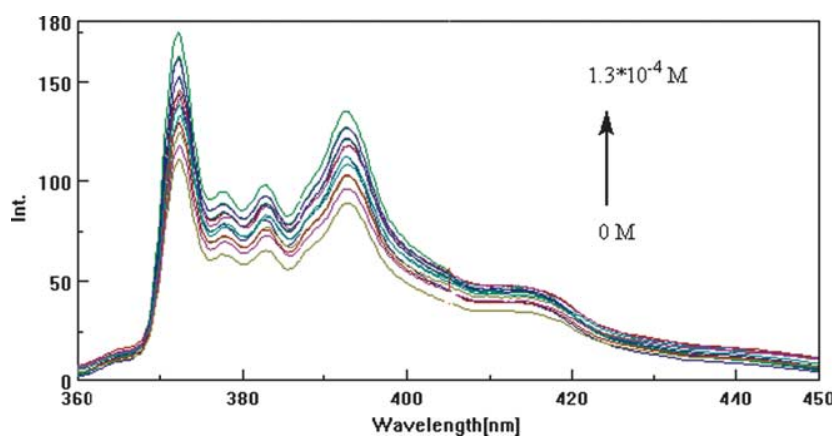

Figure 3. Fluorescence spectra of $\mathbf{P y}$ and $N-\mathrm{Cbz}-\mathrm{L}-\mathrm{Phe}$ in the presence of increasing concentrations of am- $\beta-\mathrm{CD}$ in borate buffer solution at $\mathrm{pH} 9.0$.

Job plot analysis ${ }^{16}$ had shown that the binary complex has a $(1 / 2)$ (Py-am- $\beta$-CD) stoichiometric ratio. ${ }^{11}$ However, in this complex neither of the cavities is completely filled by the Py molecule and therefore some water molecules are still present. These are in an energetically disfavoured condition. So the complex stability can be altered by adding a ternary agent. ${ }^{11,12}$ As previously reported, ${ }^{12}$ a stoichiometric ratio (1/2/2) (fluorophore-cyclodextrin-ternary agent) for ternary complexes studied was determined by means of Job plot analysis. ${ }^{16}$ The $\beta_{2}$ value for the ternary complex can be either higher or lower than that for the binary complex. A higher $\beta_{2}$ value means that the ternary complex is more stable than the binary one, while the contrary being due for a lower value. Stabilisation of the ternary complex occurs when residual cavity desolvation prevails on partial displacement of guest molecule. Of course, extensive displacement will cause ternary complex destabilisation. In our case, owing to the sandwich geometry of the binary complex Py/am- $\beta$-CD (Fig. 4) we visualise the inclusion process for the formation of a (1/2/2) (fluorophore-cyclodextrin-ternary agent) ternary complex as continuous.

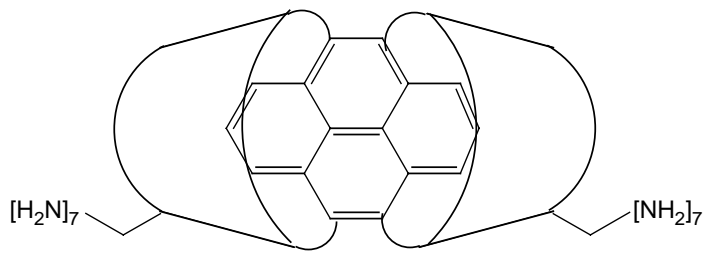

Figure 4. Schematic representation of binary complex Py/am- $\beta-C D$.

Initially, the ternary agent can displace some water molecules, increasing the stability; successively a deeper inclusion should begin to push out the fluorophore molecule, decreasing the stability. Then the $\beta_{2}$ value should show a somewhat bell shaped trend as function of the inclusion depth of the ternary agent. So the same $\beta_{2}$ value could be referred to two different situations.

The analysed properties of ternary complexes are obviously influenced by the ternary agent; that is, its side chain structure as well as its protecting group structure. In particular, the chosen protecting groups have different steric hindrance (the MR values for $\mathrm{Me}, t-\mathrm{Bu}, \mathrm{Ac}$, Boc and $\mathrm{Cbz}$ are $5.65,19.62,11.18,26.77$ and 37.20 , respectively) ${ }^{17}$ and hydrophobicity (the $\pi$ values for $\mathrm{Me}, t-\mathrm{Bu}, \mathrm{Ac}, \mathrm{Boc}$ and $\mathrm{Cbz}$ are $0.56,1.58,-0.55,1.62$ and 1.84 , respectively). ${ }^{17}$ Furthermore, different interactions can be present in the systems studied as a consequence of the different charge present on the primary rim of am- $\beta-\mathrm{CD} .{ }^{18}$ Consequently $\mathrm{pH}$ variation can be important in determining both the stability and chiral recognition ability of complex.

\subsection{Amides}

For a quick overall evaluation, data relative to amides are also shown in Figure 5.

Among the $N$-protected amino acids used in this work, the $N$-Cbz-Phe, at pH 9.0, did not allow us to determine the $\beta_{2}$ value. In fact, in this case, solutions of the ternary complex were too turbid to acquire steady-state fluorescence spectra.

As can be seen from data reported in Figure 5, in most cases (30 from 34), both at $\mathrm{pH} 8.0$ and at $\mathrm{pH} 9.0$, addition of 


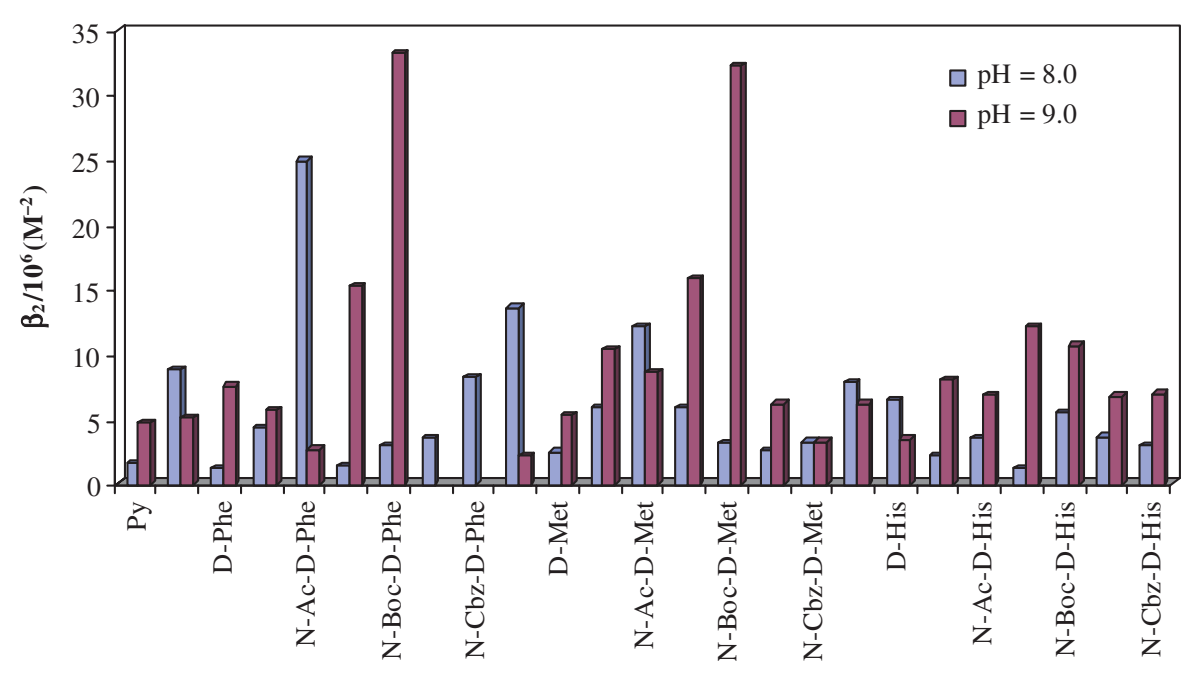

Figure 5. Stability constant values $\left(\beta_{2}\right)$ of ternary complexes formed by Py/am- $\beta-C D$ in the presence of amides.

amides stabilises the binary complex. Generally these ternary agents, present prevalently as anions, ${ }^{19}$ form more stable complexes at $\mathrm{pH} 9.0$ (13 from 16) than at $\mathrm{pH}$ 8.0. This seems to indicate that the hydrogen bonds between the carboxylate group of the ternary agents and amino groups of am- $\beta-C D$ are more efficient than electrostatic interactions, that are operative at $\mathrm{pH} 8.0$, in stabilising the system. These results are completely different from those previously obtained in the presence of the corresponding amino acids. ${ }^{11}$ In general, the amount of stabilisation, going from $\mathrm{pH} 8.0$ up to 9.0, seems to increase with hydrophobicity of the protecting group.

To evaluate the effect of $\mathrm{N}$-substitution on amino acids, data collected in this work can be compared with those, previously reported, ${ }^{11}$ dealing with the stability of the ternary complexes formed in the presence of the corresponding amino acids. As can be seen from the Table 1 , the ternary complexes of $\mathrm{L}$-amides are less stable (at $\mathrm{pH}$ 8.0) and more stable (at $\mathrm{pH}$ 9.0) than those for the corresponding amino acids. Indeed at $\mathrm{pH} 8.0$, the Coulombic interactions, operating equally in the presence of amino acids or amides, are the main contribution to stability of the ternary complex. On the other hand, at $\mathrm{pH} 9.0$, the presence of a bulky substituent on the amino group, that can increase the contribution of hydrophobic interactions, determines the higher stability of the ternary complexes formed by amides. The different behaviour shown by L- and D- derivatives going from $\mathrm{pH} 8.0$ up to 9.0 could be traced back to the occurrence of a some variation in host shape.

In fact, the am- $\beta-C D$ in its charged form has a distorted structure owing to electrostatic repulsion among the cationic ammonium groups. $^{21}$

A different trend is shown for D-amides, in fact, the ternary complexes of D-amides are, generally, more stable than those of the corresponding amino acids. His constitutes an interesting exception, at $\mathrm{pH} 8.0$ the $\mathrm{N}$-substituted complexes of His, irrespectively of D,L configuration, are less stable than those of both L- and D-amino acids.
However, data obtained show that the stability of the complexes cannot be rationalised only by considering differences in hydrophobicity or in steric hindrance of the protecting groups. Indeed, the stability of complexes formed by the Phe derivatives, at $\mathrm{pH} 8.0$, can be explained by considering the steric hindrance of the substituent present on the amino group, but the same factor does not allow us to rationalise the trend in $\beta_{2}$ values for the ternary complexes formed by derivatives of Met and His. Probably the stability of these complexes is a result of a balance between these two factors (steric hindrance and hydrophobicity) that can act in opposite directions.

In our opinion, it is important to analyse data in the light of the side chain structure of amino acids. Indeed, as both at $\mathrm{pH} 8.0$ and 9.0 the His has a charged side chain, owing to a more difficult desolvation process, it should form less stable complexes. A comparison among data reported in Table 1 shows that, in many cases, this hypothesis is confirmed. Indeed, considering the Met derivatives, with the exception of the $\mathrm{N}$-Cbz derivatives, ternary complexes formed by this amino acid are more stable than those formed by the His derivatives.
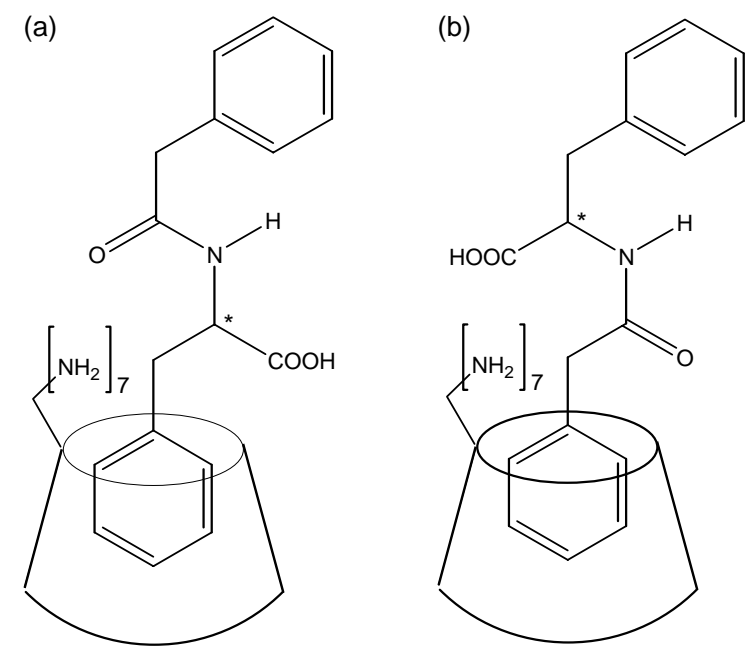

Figure 6. Schematic representation of complex formed by $\mathrm{N}$-Cbz-Phe. 
The last factor to analyse is the inclusion direction of the ternary agent. On this subject, going from $N$-Ac derivatives to $N$-Cbz derivatives there is an increase in the hydrophobicity, in particular $\mathrm{N}$-Cbz-Phe is an example of ditopic ternary agent. So, it could be reasonable to think that there will be a competition between the protecting group and the side chain for the occupancy of the residual cavity of am- $\beta-C D$ in the binary complex (Fig. 6).

However, in our opinion, in arrangement b (Fig. 6) the asymmetric carbon atom of the ternary agent should be too far from the cavity to justify the different $\beta_{2}$ values determined for the enantiomers of the same derivative and consequently their chiral recognition (see later).

\subsection{Amino esters}

The influence of electrostatic interactions on stabilisation of the ternary complexes has been investigated by esterification of amino acids. Under the experimental conditions these are prevalently present as neutral molecules. ${ }^{22}$ In Figure 7 , the stability constant values $\left(\beta_{2}\right)$ for the ternary complexes formed by Py/am- $\beta-C D$ in the presence of amino esters are shown. Among the amino esters studied, only Phe$t$ - $\mathrm{Bu}$, at $\mathrm{pH} 9.0$, did not allow us to determine the $\beta_{2}$ values, because of the high turbidity of solutions.

As can be seen from Figure 7, in most cases (14 from 18), at $\mathrm{pH} 8.0$, the addition of the amino esters increases the stability of the binary complex Py/am- $\beta-C D$, according to the exclusion of some water molecules from the residual cavity of the am- $\beta-C D$. The values collected at $\mathrm{pH} 9.0$ show a diversified behaviour. Indeed, the addition of amino esters in some cases induces an increase in stability and in some others the opposite effect is observed. However, the comparison with the $\beta_{2}$ values obtained in the presence of the corresponding amino acids ${ }^{11}$ shows that the amino esters have a very well-defined behaviour. Indeed, in general, $\mathrm{L}$-amino esters, with the exception of the L-Met- $t$-Bu at $\mathrm{pH}$ 9.0, form less stable ternary complexes as compared with the corresponding amino acids. On the contrary, the D-amino esters have a less clear behaviour. Indeed, for D-Phe the complexes of esters are more stable than those of the acid. The opposite, with the exception of the $t$-Bu ester at $\mathrm{pH} 9.0$, occurs for D-His, whereas for D-Met the order of stability changes going from $\mathrm{pH} 8.0$ to 9.0. This indicates that generally the increase in hydrophobic interactions going from the amino acid to methyl ester does not counterbalance the decrease in electrostatic interactions by ion-pairing between the amino acid anion and protonated amino groups of the am- $\beta-C D$.

In general, the stability of ternary complexes formed by the amino esters increases in the order:

\section{His $<$ Met $<$ Phe}

according to the increase of the side chain hydrophobicity.

The two chosen protecting groups (methyl and $t$-butyl) are different in their steric hindrance and hydrophobicity. The increase in steric hindrance should lead to a destabilisation of the complex; on the other hand an increase in hydrophobic interactions, going from methyl esters up to $t$-butyl esters, should lead to a stabilisation of the complex. However, collected data show that the stability of studied ternary complexes cannot be explained considering these factors separately. Indeed, the complex formed by L-PheMe, at $\mathrm{pH} 8.0$, is less stable than that formed by $\mathrm{L}-\mathrm{Phe}-t-\mathrm{Bu}$, according to lower hydrophobicity, but the D-enantiomers show an opposite stability order. Similar behaviour can be observed for the amino esters of Met at $\mathrm{pH}$ 9.0. Probably, also in this case, as in the presence of amides, stability of the ternary complex is a result of the balance between these two discordant forces and of some variation in the host shape.

\subsection{Chiral recognition}

In Table 3, the enantioselectivity ratios determined in the presence of amides or esters of amino acids, as a function of $\mathrm{pH}$ values are reported. Furthermore, for a useful comparison, enantioselectivity ratios, previously determined for ternary complexes formed in the presence of corresponding amino acids, ${ }^{11}$ are also reported.

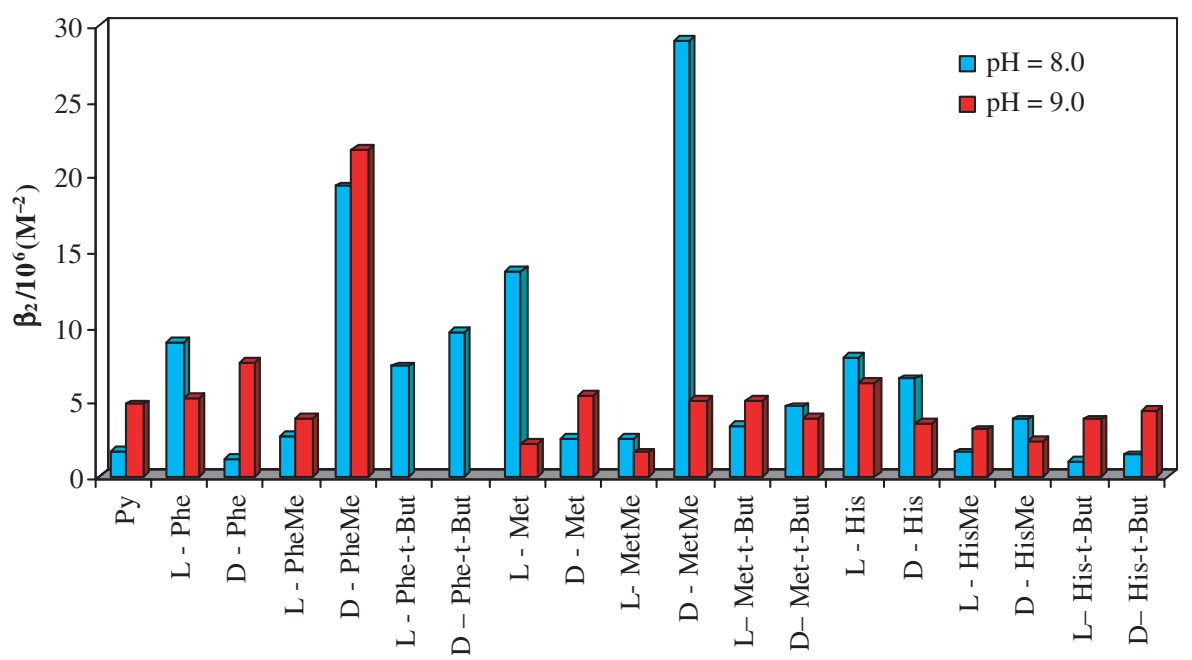

Figure 7. Stability constant values $\left(\beta_{2}\right)$ of the ternary complexes formed by $\mathbf{P y} / \mathrm{am}-\beta-\mathrm{CD}$ in the presence of amino esters. 
Table 3. Enantioselectivity ratios for ternary complexes formed by Py/am$\beta-C D$ in the presence of amides and esters of amino acids

\begin{tabular}{|c|c|c|}
\hline Ternary agent & E.r. pH $8.0^{\mathrm{a}}$ & E.r. $\mathrm{pH} 9.0^{\mathrm{a}}$ \\
\hline Phe & $7.4(\mathrm{~L}>\mathrm{D})^{\mathrm{b}}$ & $6.3\left(\mathrm{D}>_{\mathrm{L}}\right)^{\mathrm{b}}$ \\
\hline PheMe & $7.1(\mathrm{D}>\mathrm{L})^{\mathrm{b}}$ & $5.6\left(\mathrm{D}>_{\mathrm{L}}\right)^{\mathrm{b}}$ \\
\hline Phe- $t$-Bu & $1.3\left(\mathrm{D}>_{\mathrm{L}}\right)$ & n.d. \\
\hline$N$-Ac-Phe & $5.6\left(\mathrm{D}>_{\mathrm{L}}\right)$ & $2.2(\mathrm{~L}>\mathrm{D})$ \\
\hline$N$-Boc-Phe & $2.2\left(\mathrm{D}>_{\mathrm{L}}\right)$ & $2.2(\mathrm{D}>\mathrm{L})$ \\
\hline$N$-Cbz-Phe & $2.4\left(\mathrm{D}>_{\mathrm{L}}\right)$ & n.d. \\
\hline Met & $5.4(\mathrm{~L}>\mathrm{D})^{\mathrm{b}}$ & $2.5\left(\mathrm{D}>_{\mathrm{L}}\right)^{\mathrm{b}}$ \\
\hline MetMe & $11.6\left(\mathrm{D}>_{\mathrm{L}}\right)^{\mathrm{b}}$ & $3.2(\mathrm{D}>\mathrm{L})^{\mathrm{b}}$ \\
\hline Met- $t$-Bu & $1.3\left(\mathrm{D}>_{\mathrm{L}}\right)$ & $1.3(\mathrm{~L}>\mathrm{D})$ \\
\hline$N$-Ac-Met & $2.1(\mathrm{D}>\mathrm{L})$ & $1.2(\mathrm{~L}>\mathrm{D})$ \\
\hline$N$-Boc-Met & $1.8(\mathrm{~L}>\mathrm{D})$ & $2.0\left(\mathrm{D}>_{\mathrm{L}}\right)$ \\
\hline$N$-Cbz-Met & $1.3(\mathrm{D}>\mathrm{L})$ & $1.9(\mathrm{~L}>\mathrm{D})$ \\
\hline His & $1.2(\mathrm{~L}>\mathrm{D})^{\mathrm{b}}$ & $1.8(\mathrm{~L}>\mathrm{D})^{\mathrm{b}}$ \\
\hline HisMe & $2.3(\mathrm{D}>\mathrm{L})^{\mathrm{b}}$ & $1.4(\mathrm{~L}>\mathrm{D})^{\mathrm{b}}$ \\
\hline His- $t$-Bu & $1.4\left(\mathrm{D}>_{\mathrm{L}}\right)$ & $1.2(\mathrm{D}>\mathrm{L})$ \\
\hline$N$-Ac-His & $1.6\left(\mathrm{D}>_{\mathrm{L}}\right)$ & $1.2(\mathrm{~L}>\mathrm{D})$ \\
\hline$N$-Boc-His & $4.7\left(\mathrm{D}>_{\mathrm{L}}\right)$ & $1.1(\mathrm{~L}>\mathrm{D})$ \\
\hline$N$-Cbz-His & $1.2(\mathrm{~L}>\mathrm{D})$ & 1.0 \\
\hline
\end{tabular}

${ }^{\mathrm{a}}$ E.r. = enantioselectivity ratio.

${ }^{\mathrm{b}}$ See Ref. 11.

Also in this case, for a quick overall evaluation, these values are shown in Figure 8.

As can be seen from Figure 8, the binary complex Py/am- $\beta$ $\mathrm{CD}$ is able to recognise amino acids derivatives not only according to their size and shape, but also their chirality. According to the picture previously reported by Kano et al. ${ }^{23}$ about the arrangement of $\alpha$-amino acid derivatives in the cavity of the am- $\beta-C D$ or of heptakis(6-carboxymethylthio)-(6-deoxy)- $\beta-C D$, also in this case it can be supposed that the hydrophobic part of the chiral molecule is anchored by means of interactions between the carboxy or amino group of the ternary agent and the arms of the host.

The chiral discrimination ability of the binary complex Py/am- $\beta-C D$ seems to be affected by $\mathrm{pH}$ values.

The analysis of the data reported in Table 3 shows that the enantioselectivity of the studied chiral selector changes with the $\mathrm{pH}$ values. In fact at $\mathrm{pH} 8.0$ a higher affinity for D-enantiomers is shown (12 from 15), but increasing the $\mathrm{pH}$ induces a higher affinity for L-enantiomers. Moreover, enantioselectivity ratios are higher at $\mathrm{pH} 8.0$ than at 9.0. At $\mathrm{pH} 8.0$ they range from 1.2 for the $N$-Cbz-His up to 11.6 for MetMe; while at pH 9.0 they range from 1.0 for $\mathrm{N}-\mathrm{Cbz}-\mathrm{His}$ up to 5.6 for the PheMe. This result seems to indicate that the binary complex is a better chiral selector in charged rather than in its neutral form. Furthermore, above all in the presence of amides, our results seem to indicate that electrostatic interactions play a determining role in recognition of chirality in supramolecular chemistry. This agrees with what was previously reported by Kano et al. ${ }^{21}$ about the higher chiral discrimination ability of the mono(6-amino)-(6-deoxy)- $\beta$-CD and am- $\beta-C D$, in their charged form, with respect to the native $\beta-C D$.

With the exception of the His derivatives, a comparison with enantioselectivity ratios, previously determined in the presence of the corresponding amino acids, ${ }^{11}$ shows that, in all cases the binary complex is a better chiral selector for unprotected amino acids. In general, the enantioselectivity seems to be affected by the side chain structure of the amino acid; in fact the L-enantioselectivity increases going from His derivatives, to Met to Phe ones, with the increase in hydrophobicity of the side chain. Furthermore, in many cases, for the same derivative, the enantioselectivity ratio decreases going from Phe to His.

Our data show that the chiral discrimination ability, in many cases, increases with the ternary complex stability. This result agrees with Xie et al. ${ }^{24}$ who found higher enantioselectivity with stronger binding, studying the chiral discrimination ability of some homochiral molecular tweezers; but it is in disagreement with Inoue's assertions that stronger binding by cyclodextrin leads to a loss of the chiral recognition. ${ }^{25}$ Nevertheless, we believe that the direct substrate-CD interaction is not comparable with substratebinary complex interaction. Indeed, as we have previously reported, ${ }^{11}$ the former leads to the best host-guest fit, whereas the latter should consist of an acceptable arrangement of substrate into the available residual CD cavity of the binary complex.

In general, the enantioselectivity ratios determined by us are comparable or higher than those previously reported. In this light, the enantioselectivity ratio determined by Kano et al. ${ }^{21}$ for am- $\beta-C D$ in the presence of $N$-Ac amino acids ranges from 1.1 for $N$-Ac-Phe up to 1.6 for $N$-Ac-Trp. In our case, this value ranges from 1.2 for $N$-Ac-His up to 5.6 for $N$-Ac-Phe. Likewise Xie et al. ${ }^{23}$ reported enantioselectivity ratios for methyl esters of $\alpha$-amino acids ranging from 1.2

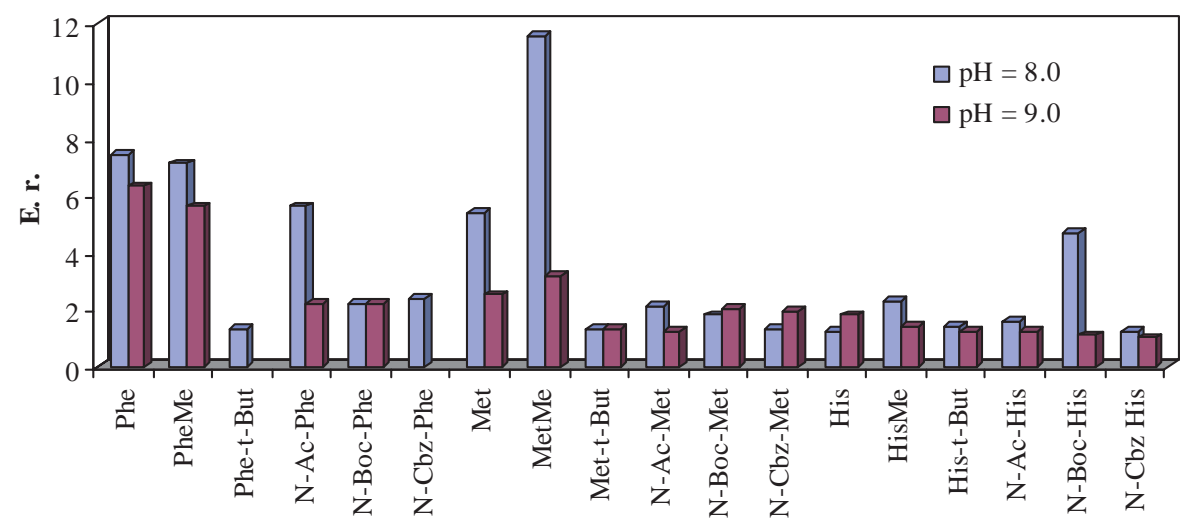

Figure 8. Enantioselectivity ratios (E.r.) as function of $\mathrm{pH}$ values. 
for AlaMe up to 7.9 for TrpMe. In our case, enantioselectivity ratios in the presence of $\alpha$-amino esters range from 1.4 for HisMe up to 7.1 for PheMe.

\section{Conclusions}

The data collected in this work show that generally the complex Py/am- $\beta$-CD forms stable ternary complexes in the presence of both the $N$ - and $O$-protected $\alpha$-amino acids studied. The actual complex stability is a consequence of the balance of some factors. Among these, steric hindrance and hydrophobicity seem to be the most important. The different stabilities determine a good chiral discrimination ability for the binary complex, making it a useful chiral selector for very dilute solution of enantiomers.

\section{Experimental}

\subsection{Materials}

Heptakis-(6-amino)-(6-deoxy)- $\beta$-cyclodextrin was synthesised and purified according to the procedure described in literature. ${ }^{26}$ The product was dried for $24 \mathrm{~h}$ in a dryer under vacuum over phosphorous pentoxide at $60^{\circ} \mathrm{C}$ and then was stored in the same apparatus at $40{ }^{\circ} \mathrm{C}$.

D-PheMe, D-MetMe, D-HisMe, D-Phe- $t$-Bu, L- and D-Met- $t$ $\mathrm{Bu}$, L- and D-His- $t$-Bu, $N$-Cbz-D-Phe, $N$-Cbz-D-Met, $N$-Ac-Land $\mathrm{D}-\mathrm{His}$ were prepared according to procedures previously reported. $^{27}$

Borate buffer solutions $(0.05 \mathrm{M})$ were prepared according to the standard procedure, using freshly double-distilled decarbonised water. The actual $\mathrm{pH}$ of the solutions was recorded using a $\mathrm{pH}$ M82 Radiometer equipped with a GK2401C combined electrode.

\subsection{Spectrometric measurements}

The solution of am- $\beta-C D$ in borate buffer $\left(1.4 \times 10^{-3} \mathrm{M}\right)$ was filtered just before use by a Millipore $0.45 \mu \mathrm{m}$ filter. Pyrene aqueous solution $\left(2 \times 10^{-6} \mathrm{M}\right)$ was prepared injecting a pyrene methanolic solution $\left(2 \times 10^{-3} \mathrm{M}\right)$ into a buffer solution, containing the ternary agent $\left(1 \times 10^{-2} \mathrm{M}\right)$. Measurement solutions were prepared by adding increasing volumes of the am- $\beta-\mathrm{CD}$ to $1 \mathrm{~mL}$ of the pyrene and ternary agent into a volumetric flask. In these solutions, the concentrations of the pyrene and the ternary agent were constant and equal to $2 \times 10^{-7}$ and $1 \times 10^{-3} \mathrm{M}$, respectively, while the concentration of the am- $\beta$-CD increased from $1.4 \times 10^{-4} \mathrm{M}$ up to $1.3 \times 10^{-3} \mathrm{M}$. All measurement solutions were deareated, before use, by Ar for $12 \mathrm{~min}$.

Steady-state fluorescence spectra were acquired with a JASCO FP-777W spectrofluorimeter. Excitation and emission slits were set at $1.5 \mathrm{~nm}$ and excitation wavelength was $337 \mathrm{~nm}$. Spectra were recorded from 360 to $450 \mathrm{~nm}$. Every spectrum was averaged over 50 scans. A suitable wavelength was chosen after recording a 'difference spectrum' by comparison to a sample without cyclodextrin and one with the highest cyclodextrin concentration.

\section{Acknowledgements}

Financial support from the University of Palermo (Funds for selected topics) and Italian MIUR within National Project 'Non-aromatic heterocyclic in stereo-controlled processes' is gratefully acknowledged.

\section{References and notes}

1. Fitzmaurice, R. J.; Kine, G. M.; Douheret, D.; Kilburn, J. D. J. Chem. Soc., Perkin Trans. 1 2002, 841-864.

2. (a) Bazzicalupi, C.; Bencini, A.; Berni, E.; Bianchi, A.; Fornasari, P.; Giorgi, C.; Valtancoli, B. Eur. J. Inorg. Chem. 2003, 1974-1983. (b) Imai, H.; Munakata, H.; Uemori, Y.; Satura, N. Inorg. Chem. 2004, 43, 1211-1213. (c) Asif, R.; Chung, D. S.; Hong, J. I. Tetrahedron Lett. 2003, 44, 4335-4338.

3. Araki, K.; Goto, M.; Furusaki, S. Anal. Chim. Acta 2002, 469, 173-181.

4. (a) You, J.-S.; Xu, X.-Q.; Zhang, G.-L.; Xiang, Q.-X.; Lan, J.-B.; Xie, R.-G. Chem. Commun. 2001, 1816-1817. (b) Gasparrini, F.; Misiti, D.; Pierini, M.; Villani, C. Org. Lett. 2002, 4, 3993-3996. (c) Chen, X.; Du, D.-M.; Hua, W.-T. Tetrahedron: Asymmetry 2003, 14, 999-1007. (d) Zheng, Y.-S.; Zhang, C. Org. Lett. 2004, 6, 1189-1192.

5. (a) Cooper, A.; MacNicol, D. D. J. Chem. Soc., Perkin Trans. 2 1978, 760-763. (b) Rekharsky, M. V.; Schwarz, F. P.; Tewari, Y. B.; Goldberg, R. N. J. Phys. Chem. 1994, 98, 10282-10288. (c) Liu, Y.; Li, L.; Li, X. Y.; Zhang, H. Y.; Wada, T.; Inoue, Y. J. Org. Chem. 2003, 68, 3646-3657. (d) Liu, Y.; Yu, C.-C.; Zhang, H.-Y.; Zhao, Y.-L. Eur. J. Org. Chem. 2003, 1415-1422.

6. Lara, K. O.; Godoy-Alcantar, C.; Eliseev, A. V.; Yatsimirsky, A. K. Org. Biomol. Chem. 2004, 2, 1712-1718.

7. (a) Hembury, G.; Rekharsky, M.; Nakamura, A.; Inoue, Y. Org. Lett. 2000, 2, 3257-3260. (b) Mwakibete, H.; Bloor, D. M.; Wyn-Jones, E. J. Inclusion. Phenom. Mol. 1991, 10, 497-505. (c) Maletic, M.; Wennemers, H.; McDonald, D. Q.; Breslow, R.; Still, W. C. Angew. Chem. 1996, 108, 1594-1596. (d) Hacket, F.; Simova, S.; Schneider, H.-J. J. Phys. Org. Chem. 2001, 14, 159-170.

8. (a) Bonomo, R. P.; Cucinotta, V.; Maccarrone, G.; Rizzarelli, E.; Vecchio, G. J. Chem. Soc., Dalton Trans. 2001, 1366-1373. (b) Corradini, R.; Paganizzi, C.; Marchelli, R.; Pagliari, S.; Sforza, S.; Dossena, A.; Galaverna, G.; Duchateau, A. Chirality 2003, 15, S30-S39. (c) Pagliari, S.; Corradini, R.; Galaverna, G.; Sforza, S.; Dossena, A.; Montalti, M.; Prodi, L.; Zaccheroni, N.; Marchelli, R. Chem. Eur. J. 2004, 2749-2758.

9. Brown, S. E.; Coates, J. H.; Duckworth, P. A.; Lincoln, S. F.; Easton, C. J.; May, B. L. J. Chem. Soc., Faraday Trans. 1993, 89, 1035-1040.

10. (a) Nardi, A.; Eliseev, A.; Bocek, P.; Fanali, S. J. Chromatogr. 1993, 638, 247-253. (b) Lelievre, F.; Gareil, P.; Jardy, A. Anal. Chem. 1997, 69, 385-392. (c) Egashira, N.; Mutoh, O.; Kurauchi, Y.; Ohga, K. Anal. Sci. 1996, 12, 503-510.

11. D’Anna, F.; Riela, S.; Gruttadauria, M.; Lo Meo, P.; Noto, R. Tetrahedron: Asymmetry 2002, 13, 1755-1760.

12. D’Anna, F.; Riela, S.; Gruttadauria, M.; Lo Meo, P.; Noto, R. Tetrahedron 2005, 61, 4577-4583. 
13. Xu, W.; Demas, J. N.; DeGraff, B. A.; Whaley, M. J. Phys. Chem. 1993, 97, 6546-6554.

14. Benesi, H. A.; Hildebrand, J. H. J. Am. Chem. Soc. 1949, 71, 2703-2707.

15. (a) Kobayashi, N.; Saito, R.; Hino, H.; Hino, Y.; Ueno, A.; Osa, T. J. Chem. Soc., Perkin Trans. 2 1983, 1031-1036. (b) Hamai, S. J. Phys. Chem. 1989, 93, 2074-2078.

16. Job, P. Ann. Chim. 1928, 8, 113-203.

17. Hansch, C.; Leo, A. J. Substituent Constants for Correlation Analysis in Chemistry and Biology; Wiley: New York, 1979.

18. Hamelin, B.; Jullien, L.; Guillo, F.; Lehn, J. M.; Jardy, A.; De Robertis, L.; Driguez, H. J. Phys. Chem. 1995, 99, $17877-17885$.

19. The $\mathrm{p} K_{\mathrm{a}}$ values of amino acid increase as a consequence of electronic effect of the N-protection. For example, in the case of $N$-acetyl glycine the $\mathrm{p} K_{\mathrm{a} 1}$, relative to dissociation of carboxylic group, moves from 2.35 to $3.67 .^{20}$ The $\mathrm{p} K_{\mathrm{a} 2}$ value, relative to dissociation of ammonium group, should be affected to an even major extent.
20. Dean, J. A. Handbook of Organic Chemistry; Mcgraw-Hill Book Company: New York, 1987.

21. Kitae, T.; Nakayama, T.; Kano, K. J. Chem. Soc., Perkin Trans. 2 1998, 207-212.

22. The $\mathrm{p} K_{\mathrm{a}}$ value for ammonium dissociation decreases as a consequence of the esterification. For example, in the case of Phe, it moves from 9.31 to $7.05 .^{20}$

23. Kano, K.; Nishiyabu, R. J. Inclusion Phenom. Macro. 2002 , 44, 355-359.

24. Du, C.-P.; You, J.-S.; Yu, X.-Q.; Liu, C.-L.; Lan, J.-B.; Xie, R.-G. Tetrahedron: Asymmetry 2003, 14, 3651-3656.

25. Rekharsky, M. V.; Inoue, Y. J. Am. Chem. Soc. 2002, 124, 813-826.

26. Ashton, P. R.; Koniger, R.; Stoddart, J. F. J. Org. Chem. 1996, 61, 903-908.

27. (a) Rachele, J. R. J. Org. Chem. 1963, 28, 2898. (b) Stephen, C. B.; Cobás, A. A.; Rapoport, H. J. Org. Chem. 1993, 58, 2369-2376. (c) Gibson, F. R.; Bergmeier, S. C.; Rapoport, H. J. Org. Chem. 1994, 59, 3216-3218. (d) Kocienski, P. J. Protecting Groups; Georg Thieme: Stuttgart, New York, 1994. 